\title{
Ocular palsies of obscure origin in South East Asia
}

\author{
C. H. TAY, Y. T. TAN, J. S. CHEAH, AND G. A. RANSOME \\ From the Medical Units of Outram and Alexandra Road General Hospitals \\ and the Department of Medicine, University of Singapore, Singapore, Republic of Singapore
}

SYNOPSIS The clinical and laboratory findings are presented of 14 patients who were recently found to have an obscure form of ocular palsy during a three year study in Singapore. The disease, which has no predilection for any age groups, races, occupations, or sex, often manifests with acute onset of unilateral or bilateral cranial nerve paralysis involving the 3rd, 4th, 6th, first two branches of the 5th, and sometimes, the 2 nd cranial nerve in various combinations. Major symptoms were diplopia, ptosis, giddiness, headache, facial numbness, proptosis, retro-orbital pain, chemosis, conjunctival irritation, blurred vision, and/or progressive blindness. Systemic complications were rare. Except for a raised erythrocyte sedimentation rate during the acute phase, exhaustive investigations-but short of a surgical exploration-were essentially noncontributory. All cleared up within two to four weeks, nine patients had spontaneous remission, while five improved only after a course of systemic corticosteroids. Two cases were left with some residual neurological deficits and one in this series had a relapse two years later. The relationship of this condition to those described outside South East Asia is discussed.

In recent years we have observed an increasing number of ocular palsies of undetermined origin in Singapore. This condition was encountered in all age groups, both sexes, and the four major racial groups in this country. There was acute or subacute onset of unilateral or bilateral ophthalmoplegias due to combined lesions of the $3 \mathrm{rd}$, 4th, 6th, and the first two sensory branches of the 5th cranial nerves. Occasionally the optic nerve was affected with disturbance of vision and progressive blindness. The presenting symptoms were mainly due to the nerve lesions and they were diplopia, ptosis, facial numbness, proptosis, retro-orbital pain, chemosis, giddiness, headache, conjunctival irritation, blurred vision, and blindness.

In the majority of cases, there was a singular absence of systemic disease. Exhaustive investigations including cerebral angiography, postnasal biopsy, immunological and viral studies-but short of an exploration of the orbits-usually drew a blank. The ocular palsies and other cranial nerve lesions often recovered fully or partially in two to four weeks either spontaneously or with the oral administration of corticosteroids.

\section{MATERIALS AND METHODS}

SUBJECTS Fourteen patients with ocular palsies of unknown causes found in two large Singapore hospitals during January 1969 to December 1971 were involved in this study. All were local residents except for three Malaysians. They were selected after careful exclusion of ocular palsies from known conditions such as those due to trauma, specific infections, endocrinopathies, collagenoses, neoplasms, vascular diseases, toxic poisoning, metabolic disorders, and degenerative diseases.

CLINICAL STUDIES A detailed history was obtained from every patient at the first interview and special reference was made to the presenting symptoms, onset of disease, previous attacks, and past illness and other associated systemic disorders. In addition to a thorough medical examination, each case had complete neurological, ophthalmological, and otorhinolaryngeal examinations. Special effort was made to exclude local common conditions such as tuberculosis, syphilis, leprosy, malaria, diabetes mellitus, thyrotoxicosis, myasthenia gravis, migraine, cerebrovascular lesions, orbital neoplasms, nasopharyngeal carcinoma, autoimmune diseases such as systemic lupus erythematosus and temporal arteritis, and common viral infections-for example, dengue virus, ECHO virus, Coxsackie virus, and herpes virus. 
A blind postnasal biopsy was carried out in all cases to rule out nasopharyngeal malignancy.

LABORATORY STUDIES The following investigations were carried out: haemoglobin, full blood count, haematocrit, peripheral blood film, erythrocyte sedimentation rate (Westergren), blood film for malaria and microfilarial parasites, serum electrolytes, blood urea, serum protein electrophoresis, serum cholesterol, serum calcium, inorganic phosphorous and amylase, blood uric acid, serum folic acid and vitamin $B_{12}$, protein bound iodine, fasting plasma cortisol, blood cultures, LE phenomenon, rheumatoid factor, antinuclear antibody factor, $T_{3}$ resin uptake, liver function tests, glucose tolerance test, urinary full and microscopic examinations, urinary and sputum cultures, stool for ova and occult blood, complete examination of the cerebrospinal fluid (CSF), CSF culture, blood and CSF examination for VDRL and FTA-ABS (fluorescent treponemal antibody absorption test), urinary 17hydroxycorticosteroid and ketosteroids, bone marrow study, edrophonium test, earclip for acid-fast bacilli, blood and stool for viral studies especially for dengue virus, Japanese B encephalitis virus, ECHO virus, Coxsackie virus, and herpes virus, electrocardiograms, radiological examinations of the chest, abdomen, skull, pituitary fossa, cervical spine, both orbits, frontal and maxillary sinuses, both optic foramina, and a bilateral carotid angiogram.

\section{RESULTS}

During the three year study period in Singapore, 14 cases of obscure ocular palsies were found, an average of about five cases a year. The disease had no special predilection for any age groups, sexes, race, or occupations (Table 1). The youngest patient was 16 years old and the oldest, aged 69 years. The number of Chinese cases here merely reflects the proportion of this race in Singapore.

Half the patients in this series had sudden onset of ophthalmoplegia, six were seen during the first two weeks of onset and the remainder two weeks to six months after the initial symptoms. Nine had unilateral right-sided ophthalmoplegia, three had left-sided ocular lesions and two showed bilateral ocular involvement.

The neurological and ocular symptoms and signs are listed in Table 2. Preceding symptoms included coryza (two cases), transient acute bilateral conjunctivitis (two cases), and vague giddiness (nine cases). A nonspecific mild head-
TABLE 1

DISTRIBUTION OF PATIENTS BY AGE, SEX, RACE, AND OCCUPATION (14 PATIENTS)

\begin{tabular}{|c|c|}
\hline & No. of patients \\
\hline $\begin{array}{c}\text { Age (yr) } \\
10-19 \\
20-29 \\
30-39 \\
40-49 \\
50-59 \\
60-69\end{array}$ & $\begin{array}{l}3 \\
2 \\
3 \\
2 \\
2 \\
2 \\
2\end{array}$ \\
\hline Total & 14 \\
\hline $\begin{array}{l}\text { Sex } \\
\quad \text { Males } \\
\text { Females }\end{array}$ & $\begin{array}{l}6 \\
8\end{array}$ \\
\hline Total & 14 \\
\hline $\begin{array}{l}\text { Race } \\
\text { Chinese } \\
\text { Indian } \\
\text { Malay } \\
\text { Eurasian }\end{array}$ & $\begin{array}{l}7 \\
4 \\
2 \\
1\end{array}$ \\
\hline Total & 14 \\
\hline $\begin{array}{l}\text { Occupation } \\
\text { Housewife } \\
\text { Artisan } \\
\text { Student } \\
\text { Merchant } \\
\text { Clerk } \\
\text { Cook } \\
\text { Waitress }\end{array}$ & $\begin{array}{l}5 \\
3 \\
2 \\
1 \\
1 \\
1 \\
1\end{array}$ \\
\hline Total & 14 \\
\hline
\end{tabular}

TABLE 2

NEUROLOGICAL AND OCULAR SYMPTOMS AND SIGNS (14 PATIENTS)

\begin{tabular}{lc}
\hline & No. of patients \\
\hline Symptoms & 14 \\
Diplopia and ptosis & 10 \\
Facial numbness & 9 \\
Giddiness & 9 \\
Nonspecific headache & 9 \\
Exophthalmos & 6 \\
Swelling of eyelids & 4 \\
Retro-orbital pain & 2 \\
Conjunctival hyperaemia and irritation & 2 \\
Blurred vision & 1 \\
Progressive blindness & \\
Signs & 14 \\
Paralysis of 3rd cranial nerve & 13 \\
Paralysis of 4th cranial nerve & 12 \\
Paralysis of 6th cranial nerve & 10 \\
5th cranial nerve lesions- & \\
Sensory loss over ophthalmic branch (9) & \\
Sensory loss over maxillary branch (1) & 9 \\
Proptosis (18-26 mm) & 6 \\
Chemosis & 2 \\
Papilloedema & 1 \\
Optic atrophy & \\
\hline
\end{tabular}


ache, sometimes hemicranial in distribution on the side of the ocular lesion, was found in nine patients and it tended to improve after two weeks. The ocular palsies were responsible for diplopia (14 patients), ptosis and swelling of the eyelids (14 and six patients respectively), and exophthalmos of varying degrees (nine patients). Facial numbness with hypoaesthesia in the territory of the ophthalmic and maxillary branches of the fifth cranial nerve was found in 10 patients and four had mild to moderate degrees of dull, boring pain in and around the affected orbits. Numbness and pain often disappeared by the second or third week. Two cases were found to have conjunctival hyperaemia from irritations. Only two complained of blurred vision from optic nerve involvement, and one with a severe form of papilloedema became blind from optic atrophy.

The commonest clinical signs were complete ophthalmoplegia caused by paralysis of the $3 \mathrm{rd}$, 4th, and 6th cranial nerves (14 cases, 13 cases, and 12 cases respectively) (Table 2). Total or partial paralysis of these nerves in various combinations was encountered and in seven patients the affected pupils were dilated and failed to react to light and accommodation.

Mild to moderate degrees of proptosis measuring from $18 \mathrm{~mm}$ to $26 \mathrm{~mm}$ were found in nine patients. They were earlier suspected of having orbital tumours, pseudotumour of the orbit, or thyrotoxicosis. Of the 10 patients with trigeminal nerve involvement, nine had a first division lesion with hypoaesthesia and diminished corneal reflexes, while one had a second division lesion. The mandibular and the motor branches of this nerve were not affected. Except for two patients with optic nerve involvement, the other cranial nerves were not affected. Long tract signs were absent and the rest of the neurological system was essentially normal.

Systemic complications were not observed, but a number of associated conditions were found in this group of patients-namely, hypertension (four patients), diabetes mellitus (two patients), ischaemic heart disease and gout (one patient each). All these patients were already on treatment for their respective illnesses before the onset of ocular palsies, and there seemed to be no definite relation between them.
LABORATORY INVESTIGATIONS Haemoglobin and total white cell counts were generally normal; the former ranged from 10.5 to $14.8 \mathrm{~g} / 100 \mathrm{ml}$. and the latter, from 4,300 to $10,700 / \mathrm{mm}^{3}$. Differential white cell counts, haematocrits, and peripheral blood smear pictures were also normal. Only six patients showed raised erythrocyte sedimentation rate (ESR) during the acute phase (45-135 mm in the first hour). On recovery, the ESR returned to normal. Except for those patients with known associated diseases listed above, all the haematological, biochemical, and radiological investigations were essentially normal. Only three out of 14 patients revealed some cerebrospinal fluid abnormalities such as a raised cell count to 16 lymphocytes per $\mathrm{mm}^{3}$ and a total CSF protein of 40 to $70 \mathrm{mg}$ per $100 \mathrm{ml}$. The VDRL and bacterial cultures of CSF were negative. Normal results were also obtained in all the metabolic, endocrine, immunological, and viral investigations. There was no evidence of tuberculosis, syphilis, leprosy, bacterial infection, parasitic infestations, toxic or degenerative disorders or endocrine abnormalities. Edrophonium tests were repeatedly negative. Blind postnasal biopsy in 12 patients revealed normal histology. All radiological investigations, including bilateral carotid angiograms, revealed no abnormalities. No vascular lesions were noted.

MANAGEMENT AND CLINICAL COURSE Treatment Nine of the 14 patients received no special medication other than analgesics and vitamins as they showed spontaneous improvement during the period of observation. The other five received oral corticosteroids, starting with 45 to $60 \mathrm{mg}$ prednisolone a day for the first two weeks and reducing to 10 or $15 \mathrm{mg}$ a day thereafter as maintenance in those who had protracted paralysis for over a month and also the two cases with early optic nerve involvement. Orbital exploration and biopsy were considered in these cases but in view of the benign nature and selflimiting tendency in this type of ocular palsy as well as the reported high morbidity attending any surgical interventions (Offret, 1951; Coop, 1961 ; Mortada, 1970), the procedure was not carried out.

Clinical course Complete remission was noted in 12 patients two to four weeks after the onset 
TABLE 3

CLINICAL FEATURES OF OPHTHALMOPLEGIAS OF OBSCURE ORIGIN

\begin{tabular}{|c|c|c|c|c|c|c|}
\hline & \multicolumn{6}{|c|}{ Clinical features } \\
\hline & $\begin{array}{l}\text { Present } \\
\text { disease }\end{array}$ & $\begin{array}{l}\text { Collier's } \\
\text { syndrome }\end{array}$ & $\begin{array}{l}\text { Superior orbital } \\
\text { fissure syndrome }\end{array}$ & $\begin{array}{l}\text { Orbital apex } \\
\text { syndrome }\end{array}$ & $\begin{array}{l}\text { Orbital pseudo- } \\
\text { tumour syndrome }\end{array}$ & $\begin{array}{c}\text { Painful } \\
\text { ophthalmoplegia }\end{array}$ \\
\hline & \multicolumn{6}{|c|}{ Reference, country } \\
\hline & $\begin{array}{c}\text { (1973) } \\
\text { Singapore, } \\
\text { Malaysia }\end{array}$ & $\begin{array}{l}\text { (Collier, 192I) } \\
\text { G.B. }\end{array}$ & $\begin{array}{c}\text { (Mortada, 196I) } \\
\text { Egypt }\end{array}$ & $\begin{array}{l}\text { (Ingalls, 1953) } \\
\text { U.S.A. }\end{array}$ & $\begin{array}{c}\text { (Coop, 1961; } \\
\text { Jellinek, 1969) } \\
\text { G.B. }\end{array}$ & $\begin{array}{c}\text { (Mathew and } \\
\text { Chandy, 1970) } \\
\text { India }\end{array}$ \\
\hline Age group & All ages & Young adults & $\begin{array}{l}\text { Young adults, } \\
\text { middle-age }\end{array}$ & Adults & $\begin{array}{l}\text { Middle-age } \\
\text { and elderly }\end{array}$ & Elderly \\
\hline Sex ratio & Equal & Mostly males & Equal & Equal & Equal & Mostly males \\
\hline Unilateral ophthalmoplegia & + & + & + & + & + & + \\
\hline Retro-orbital pain & + & + & + & + & + & +++ \\
\hline Facial numbness & + & + & + & + & + & + \\
\hline $\begin{array}{l}\text { Proptosis } \\
\text { 3rd, 4th, 6th cranial nerve }\end{array}$ & + & + & + & + & $++t$ & + \\
\hline $\begin{array}{l}\text { involvement } \\
\text { Sensory 5th cranial nerve }\end{array}$ & + & + & + & + & + & + \\
\hline involvement & + & + & + & + & + & + \\
\hline Optic nerve involvement & + & + & + & ++ & + & + \\
\hline Spontaneous remission & + & + & + & + & + & + \\
\hline Dramatic response to steroids & + & + & + & + & + & + \\
\hline Relapses & + & + & + & + & + & + \\
\hline
\end{tabular}

of illness or after a course of oral corticosteroid. These include nine cases with spontaneous recovery and three with steroid therapy. The ocular palsy returned to normal, pain and numbness disappeared, ptosis and proptosis receded and vision was restored. Two, however, had only partial recovery in spite of oral prednisolone treatment for six to nine months. One patient developed right optic atrophy with blindness and the other was left with a residual left rectus palsy. In this study, only one young girl had a relapse two years after recovering from a rightsided ocular paralysis. In both instances, she recovered rapidly with oral prednisolone within a fortnight. The second attack also affected the right eye.

\section{DISCUSSION}

Combined paralysis of the 3rd, 4th, and 6th ocular nerves, the first two sensory branches of the 5th cranial nerves, and, sometimes, the optic nerve, are often attributed to lesions present in the orbits or the cavernous sinus, because these nervous structures are topographically proximal to each other as they emerge from the superior sphenoidal fissure, the foramen rotundum, and the optic foramen respectively. Some of the known lesions reported are trauma, pyogenic infections, tuberculosis, syphilis, tumours of the bony skull, meninges and pituitary gland metastatic neoplasm, and vascular lesions like congenital berry aneurysms or arteriovenous fistulae (Mettetal, 1927; Jefferson, 1938; Hole and Rötth, 1940; Hirschfeld, 1958).

There is however, an interesting group of ocular palsies involving these cranial nerves for which no cause has been found. In a survey of 1,000 cases with ocular paralysis, Rucker (1958) found $28 \%$ with this obscure condition. Many cases have been documented, but under a variety of syndromes and names. This is largely because the primary aetiology is still not determined and the cases were described according to the presenting symptoms, clinical findings, and other nonspecific histological findings such as granuloma, fibrosis, myositis, neuritis, arteritis, lymphomatosis, periostitis, and so forth. Examples of these conditions are the Collier's syndrome (1921), the superior orbital fissure syndrome (Rochon-Duvigneaud, 1896; Mortada, 1961 ; Lakke, 1962), the pseudoblastoma syndrome (Marbaix and van Duyse, 1921), the 'granuloma bizarre de l'orbite' (Redslob, 1935), the orbital apex syndrome (Ingalls, 1953; Mortada, 1961), the 'nonspecific granuloma of the orbit' (Easton and Smith, 1961), the orbital pseudotumour syndrome (Williamson-Noble, 
1926; Jellinek, 1969), and the Tolosa-Hunt syndrome or 'painful ophthalmoplegia' (Tolosa, 1954; Smith and Taxdal, 1966; Mathew and Chandy, 1970) to mention a few.

Most patients in this group of 'idiopathic' ocular palsies possess some or all of the following clinical features: unilateral or bilateral ophthalmoplegias due to complete or partial paralysis of the $3 \mathrm{rd}, 4 \mathrm{th}$, and 6th cranial nerves (though Jellinek's cases (1969) had more ocular muscular involvement), ptosis, chemosis, proptosis of varying severity, hemicranial headache, giddiness, diplopia, facial numbness and pain, trigeminal hypoaesthesia on the affected side, retro-orbital or periorbital pain and tenderness of the eyeball, blurred vision, and blindness from papilloedema and optic atrophy. Many investigations failed to reveal a cause but the ESR is often found to be raised during the early phase. Spontaneous remission is frequent and a dramatic response to corticosteroid is usually observed. Another feature of this group is the multiple relapses after apparent recovery.

Thus it is apparent that the disease found in our patients falls into the same category as this 'idiopathic' group. However, as shown in Table 3, there are some minor features which differentiate it from five other common conditions in this group as reported from England, America, Egypt, India, and other areas.

Our patients came from all age groups. There was no difference between sexes as found with Collier's syndrome and the 'painful ophthalmoplegias' (Mathew and Chandy, 1970). There were fewer patients with optic nerve lesions, marked proptosis and facial pain such as in the 'orbital apex syndrome' (Ingalls), the orbital pseudotumour syndrome (Coop, 1961; Jellinek, 1969), and the painful ophthalmoplegia (Mathew and Chandy, 1970) as these are the main diagnostic clinical criteria of the last three conditions.

In the absence of systemic and local diseases, giddiness and hemicranial headache may be explained by the acute ocular imbalance and reactive muscle tension caused by the ophthalmoplegia. Proptosis and chemosis with conjunctival hyperaemia are secondary to paresis of ocular muscles with venous congestion and tissue oedema. The proptosis is partly due to the subsequent lengthening of the relaxed muscles as it is easily replaced into the orbit manually.
The cause of the nervous lesions is unknown, although we have excluded all known diseases. Nasopharyngeal carcinoma, a common cause of ocular palsies in Singapore found in 30 to $40 \%$ of such cases (Shanmugaratnam, 1965), has been carefully excluded. The viral theory from common local viruses was not borne out, although four patients had preceding influenza-like symptoms and conjunctivitis. It is also not possible that there are close connections between the ocular palsies and some of the associated diseases found in our patients, because the latter had been well controlled before the neurological onset. Moreover, the clinical features and course were entirely dissimilar to the primary disease. The raised ESR and the slight CSF abnormalities in some of our patients have been previously observed by other authors (Jellinek, 1969). This observation together with the marked improvement after steroid administration have led many workers to postulate an immunological or allergic mechanism for the polyneuritis of these ocular nerves (Jellinek, 1969; Mathew and Chandy, 1970; Smith and Taxdal, 1970). Though not fully supported, there have been reports of this disorder in association with other autoimmune diseases such as periarteritis nodosa, temporal arteritis, and Wegener's granuloma (Hope-Robertson, 1956; Faulds and Wear, 1960; Åström and Lidholm, 1963).

The favourable outcome and dramatic response to steroids has been used as a therapeutic test if spontaneous remission is slow and if there is no means of carrying out a battery of investigations to exclude other causes. This procedure is probably preferable in this region where the disease is common and benign, since surgical exploration would risk a high incidence of blindness, as reported elsewhere (Offret, 1951 ; Vances and Dobrescu, 1960). Histological changes from biopsy of ocular muscles, orbital fat, nerve sheaths, and lachrymal glands are often nonspecific, consisting of lymphocytic follicle formation, perivascular and focal lymphocytic infiltrations, oedema, and fibrosis (Forrest, 1949; Coop, 1961; Easton and Smith, 1961; Jellinek, 1969).

The spontaneous remission and the rapidity of recovery have been earlier observed by Collier (1921) who remarked that this group of obscure ocular palsies showed a close analogy 
to the common Bell's palsy in the clinical presentation and course. This is true in this and many other series.

In conclusion, the ocular palsies seen in our patients from Singapore and Malaysia are almost similar to those reported in other parts of the world, but with minor differences. This group of obscure ocular palsies with distinct features and clinical course should be redesignated as 'idiopathic ophthalmoplegia' to prevent the confusion of names found at the moment. Alternatively, 'Collier's syndrome' may be considered, since it was he who first drew attention to this group of interesting but obscure forms of ophthalmoplegia.

\section{REFERENCES}

Åström, K. E., and Lidholm, S. O. (1963). Extensive intracranial lesions in a case of orbital non-specific granuloma combined with polyarteritis nodosa. Journal of Clinical Pathology, 16, 137-143.

Collier, J. (1921). Discussion on ocular palsies. Proceedings of the Royal Society of Medicine, Sections of Neurology and Ophthalmology, 14, 10-11.

Coop, M. E. (1961). Pseudotumour of the orbit. A clinical and pathological study of 47 cases. British Journal of Ophthalmology, 45, 513-542.

Easton, J. A., and Smith, W. T. (1961). Non-specific granuloma of orbit ('orbital pseudotumour'). Journal of Pathology and Bacteriology, 82, 345-354.

Faulds, J. S., and Wear, A. R. (1960). Pseudotumour of the orbit and Wegener's granuloma, Lancet, 2, 955-957.

Forrest, A. W. (1949). Intraorbital tumors. Archives of Ophthalmology, 41, 198-232.

Hirschfeld, L. (1858). Quoted by Lakke, J. P. W. F. (1962) in Superior orbital fissure syndrome. Report of a case caused by local pachymeningitis. Archives of Neurology, 7, 289300.

Holt, H., and Rötth, A. de (1940). Orbital apex and sphenoid fissure syndrome. Archives of Ophthalmology, 24, 731-741.

Hope-Robertson, W. J. (1956). Pseudo-tumour of the orbit as a presenting sign in periarteritis nodosa. Transactions of the Ophthalmological Society of New Zealand, 8, 56-66.
Ingalls, R. G. (1953). Tumors of the Orbit and Allied Pseudo Tumors. Thomas: Springfield, Ill.

Jefferson, G. (1938). On the saccular aneurysms of the internal carotid artery in the cavernous sinus. British Journal of Surgery, 26, 267-302.

Jellinek, E. H. (1969). The orbital pseudotumour syndrome and its differentiation from endocrine exophthalmos. Brain, 92, 35-58.

Lakke, J. P.. W. F. (1962). Superior orbital fissure syndrome. Report of a case caused by local pachymeningitis. Archives of Neurology, 7, 289-300.

Marbaix, and Duyse, D. van (1921). Pseudoblastome de l'orbite. Archives d'Ophtalmologie, 38, 466-479.

Mathew, N. T., and Chandy, J. (1970). Painful ophthalmoplegia. Journal of the Neurological Sciences, 11, 243-256.

Mettetal, P. (1927). Du Syndrome Syphilitique de l'Apex Orbitaire. Thesis: Lyon.

Mortada, A. (1961). Superior orbital fissure syndrome of uncertain aetiology. Report of ten cases. British Journal of Ophthalmology, 45, 662-671.

Mortada, A. (1970). Spontaneously resolving unilateral ophthalmoplegia with paralytic proptosis of idiopathic origin. British Journal of Ophthalmology, 54, 819-822.

Offret, G. (1939). Les Myosites Chroniques dans le Cadre des Myosites Orbitaires. Soin: Paris.

Redslob, E. (1935). Granulome bizarre de l'orbite. Bulletin de la Société d'Ophtalmologie de Paris, 47, 257-262.

Rochon-Duvigneaud (1896). Quelques cas de paralysie de tous les nerfs orbitaires. Archives d'Ophtalmologie, 16, 746-760.

Rucker, C. W. (1958). Paralysis of the third, fourth and sixth cranial nerves. American Journal of Ophthalmology, 46, 787-794.

Shanmugaratnam, K. (1965). Nasopharyngeal carcinoma in Singapore. Anno Accademico 1964-1965, 56, 300-316.

Smith, J. L., and Taxdal, D. S. R. (1966). Painful ophthalmoplegia. The 'Tolosa-Hunt syndrome', American Journal of Ophthalmology, 61, 1466-1472.

Tolosa, E. (1954). Periarteritic lesions of the carotid siphon with the clinical features of a carotid infraclinoidal aneurysm. Journal of Neurology, Neurosurgery, and Psychiatry, 17, 300-302.

Vancea, P., and Dobrescu, G. (1960). Myosite orbitaire chronique de nature indéterminée. Archives de Ophtalmologie, 20, 711-722.

Williamson-Noble, F. A. (1926). Inflammatory pseudotumour of the orbit. British Journal of Ophthalmology, 10, 65-78. 